\title{
El individuo, la población, uno mismo. El vínculo afectivo en la poesía amorosa de Juan del Valle y Caviedes
}

\section{The individual, the population, oneself. The affective bond in the}

"Iove" poetry of Juan del Valle y Caviedes

DOI: $10.12957 /$ ek.2016.25049

Dr. Facundo Ruiz

ilh@filo.uba.ar

Instituto de Literatura Hispanoamericana Universidad de Buenos Aires | CONICET

La cuestión de la conducta y su valor político resaltan, en el siglo XVII y en la ciudad barroca, el complejo vínculo entre arte y religión. Este vínculo, especialmente en su sentido "afectivo", ha sido objeto de la poesía de tradición amorosa no menos que de la especulación teológica y, en ambos casos, singularmente relevante en la América colonial y para sus grupos letrados. En este sentido, la poesía amorosa de Juan del Valle y Caviedes (1645-1698) ofrece no sólo una zona poco explorada, pero bien desarrollada, de su obra poética (siempre privilegiada y descripta como satírica) sino un contrapunto ético-estético fundamental respecto de la obra amorosa sorjuanina y su concepción, clave entonces para organizar, a nivel continental, esta cuestión en su amplitud literaria e histórica.

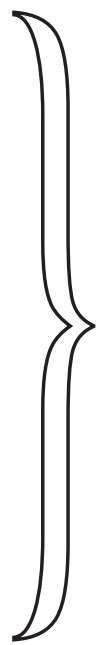

PALABRAS-CLAVE Juan del Valle y Caviedes. Poesía Amorosa. Arte y Política

The matter of conduct and its political value highlight, in the XVII century and in the baroque city, the complex bond between art and religion. This bond, especially in its "affective" meaning, has been not only an object of love poetry but also of theological speculation and, in both cases, singularly relevant in colonial America and its lettered men and women. In this sense, the love poetry of Juan del Valle y Caviedes (1645-1698) offers not only an unexplored -but well developed- field in his work (always described and privileged as "satyrical") but an ethical-aesthetic fundamental counterpoint with sor Juana's poetry and her conception of love. This will organize the matter of "love" in a continental approach and in the literary and historical amplitude it deserves.

KEY-WORDS Juan del Valle y Caviedes. Love Poetry. Art and politic 
La cuestión de la conducta y su problemática teológico-política evidencian, en el siglo XVII y en la ciudad barroca, el complejo y productivo vínculo entre arte y religión, expresado -según el orden poético- en el tenso vaivén entre una moral coactiva y una ética facultativa, entre un orden jurídico (de los deberes y obligaciones) y un orden político (de los poderes y prácticas). En este sentido, puede vislumbrarse un vínculo distinto que refiere no sólo a la realidad donde ocurre (vínculo urbano) y a la cifra de su práctica (vínculo político-religioso) sino a quien efectivamente se constituye en agente de su acción y, más aún, a los modos de constitución o agencias que hacen de la singularidad humana (ese modo de conducirse) un individuo político (ese modelo de conducta) y, de éste, un sujeto común (esa modulación conducida). Este vínculo es el afectivo, que -menos individual que singular- se organiza en torno al humano ${ }^{1}$ y su deseo, que "es la esencia misma del hombre en cuanto es concebida como determinada a hacer algo en virtud de una afección cualquiera que se da en ella (...) para su conservación" (Spinoza, Ética, III, def. I; 1984: 227).

Este vínculo, especialmente en el siglo XVII, manifiesta una articulación histórica notable que distiende ética y ascética: el "entrenamiento práctico indispensable [ascética] para que el individuo se constituya como sujeto moral [ética]" cobrará con el cristianismo "una autonomía parcial y relativa. Y ello de dos modos: habrá desvinculación entre los ejercicios que permiten gobernarse a uno mismo [askẽsis moral] y el aprendizaje de lo que es necesario para gobernar a los demás [paideia del hombre libre]; habrá desvinculación también entre los ejercicios en su forma propia [askẽsis] y la virtud [ética], la moderación [enkrateia], la templanza [sophrõsynẽ] a las que sirven de entrenamiento" (Foucault, 2003: 2, 74-5). No sólo se asiste a un momento particularmente intenso de lo que Deleuze llamó el "largo error" (2012: 35) que confunde ley con mandamiento y mandamiento con obligación moral de comprender, sino al punto en el cual dicha confusión complica además una distensión - esa "autonomía parcial y relativa" de la que habla Foucault- entre cuerpo y espíritu. La relación entre cuerpo y espíritu, la consideración de ese vínculo, hace del "vínculo afectivo" una noción común cuya relevancia y sentido políticos resultaban muy claros en el siglo XVII, no sólo etimológicamente (en tanto vinculum alude, en latín, a una ligadura tan precisa como la que el vencedor imponía a los vencidos, cf. Scavino, 2010 y Bruno, 2007), sino lógicamente, en tanto refiere a cierta relación de orden y conexión entre partes (entre cuerpo y espíritu, entre cosas e ideas, entre humano, individuo

1 "Utilizamos en el texto la palabra humano en lugar de hombre, pues consideramos que lleva razón la crítica de género en cuanto al uso de este último vocablo. Nos parece inadecuada la traducción usual del der Mensch alemán como el hombre, cuando en realidad es el humano sin distinción de género, pues el hombre es der Mann." Zaffaroni (2012: 23). 
y sujeto); esto es, en tanto todo vínculo afecta el problema político de la participación: ¿cómo se compone comunidad, se practica lo común, se entiende lo comunitario? Es ese vínculo, vale decir: su proceso de distensión-confusión, el que -bajo la condición del amor- se expresa distintamente en la poesía de sor Juana Inés de la Cruz y de Juan del Valle y Caviedes.

\section{Analítica amorosa: el deseo de razón}

La poesía amorosa de Juan del Valle y Caviedes (1645-1698) presenta una configuración peculiar en la que claramente se distinguen dos modalidades organizadas en tres zonas que -reunidas-constituyen buena parte de su obra poética pero que, al mismo tiempo, exhiben una desarticulación muy expresiva del corpus cavediano. Las tres zonas, que las ediciones de su obra completa siguen con variantes, distinguen visiblemente una poesía amorosa y una sátira amorosa (modalidad lírica) y, por último, los "bailes" o pequeñas piezas teatrales (modalidad dramática). ${ }^{2}$ A diferencia de lo que ocurre con la poesía amorosa sorjuanina (cf. Ruiz 2015 y 2014), en la obra de Valle y Caviedes la reunión-distinción de esas zonas no es estrictamente retrospectiva ni producto de una decisión editorial sino -y en buena medida- ya se percibe en la concepción de su "cuerpo de Libro" (n7, v.126) que constaba de más de una sección, organizadas por temas u objetos indicados en uno de los dos títulos posibles: "Diente del Parnaso, que trata de diversas materias, contra Médicos, de Amores [o versos amorosos, según el manuscrito], a lo Divino, Pinturas y Retratos". Así nos encontramos con un corpus cavediano compuesto por "diversas materias", una de las cuales es el amor (más precisamente: los amores). Pero, como se sabe, se trata de corpus cadavérico: "Y habiendo escrito este corto / cuerpo de Libro, que logra / título de cuerpo muerto / pues vivezas no le adornan" ( $\mathrm{n}^{\circ} 7$, vv.125-8). Muerto o enfermo, el corpus cavediano expresa no sólo una "guerra física" sino también ciertas "proezas medicales” (según el otro título posible). ${ }^{3}$

2 La edición de Reedy (Ayacucho 1984) distingue unos "Poemas amorosos" (n²17-254), luego - dentro de "Poemas satíricos y burlescos" (n०1-163) - no sub-distingue y, por último, las tres "Piezas dramáticas" $\left(\sin n^{\circ}\right)$. La edición de Cáceres (Banco de Crédito del Perú 1990) diferencia una "Lírica amatoria o de sabor bucólico" (n²29-265), luego - dentro de "Poesía satírica" ( $\left.n^{\circ} 1-157\right)$ - sub-distingue una "Aguda y mordaz" (1-92) donde se encuentra "Contra mujeres de vida disoluta" (n78-92) y, por último, el "Teatro" (n²66-268). Dado que seguiré la edición de Cáceres, para facilitar la referencia indicaré el número de poema $\left(\mathrm{n}^{\circ}\right)$ y de verso/s (v. o vv.). De ser útil o necesario, me referiré a la edición de Reedy; en ese caso, aclararé: AY o BCP.

3 El problema de el/los título/s y manuscritos, y la forma en que cada editor los lee y consigna, es arduo y supone un trabajo distinto al que aquí se intenta (cf. Lorente Medina 2005 y Cabanillas Cárdenas 2009). En cualquier caso: de los 8 manuscritos que maneja Reedy, Diente del Parnaso, que trata de diversas materias, contra Médicos, de Amores [o versos amorosos], a lo Divino, 
Todo lo cual advierte sobre dos rasgos constitutivos de la poesía amorosa de Valle y Caviedes, pues se trata de una constitución fragmentaria y de una fragmentación estilística: lo uno pues descompone -bajo condición "amorosa"- un corpus según sus materias y exhibe analíticamente un entero inacabado en sus miembros, lo que explica - por otra parte- que dichos poemas funcionen como soporte para especulaciones sobre las prácticas sociales y sexuales de una época y una ciudad (coloniales), sobre las inclinaciones morales y sentimentales de un escritor, o sobre los accidentes históricos de una "clase" (criolla); lo otro puesto que pone -bajo condición "vincular"- dichas composiciones poéticas en estrecha relación con un modo de componer literatura y, más aún, con un modo terapéutico de recomponer un corpus (cadavérico), lo que implica -por otra parte- que dichos poemas permitan especular sobre su comprensión del acto literario y el conjunto de relaciones que constituyen ese corpus y su idea.

En este sentido (o entre estos límites), la indeleble e imaginaria impronta biográfica del escritor Valle y Caviedes (cf. Ruiz 2009), ese "truhán-devoto" -de tinte más popular para Gutiérrez y más excéntrico o "fin de siglo" para Palma- que a principios del siglo XX es ya un "Villon criollo" (Sánchez, 1939), da cuenta de una intervención muy singular en lo que respecta al vínculo afectivo, organizado en torno al humano y su deseo y, por tanto, en la lectura de sus composiciones amorosas, puesto que si por un lado retrata -al decir de Sánchez- "en dos líneas sus principales temores y aficiones: la mujer y el médico, el amor y el emplasto. Lo uno para el alma; para el cuerpo lo otro" (1951: 52); al mismo tiempo, estos temores y aficiones exhiben "la acuciosidad con que el autor se fija detalladamente en la descomposición de la naturaleza", de donde Hopkins Rodríguez "vislumbra un anhelo de superación de los impulsos que aferran al hombre a la existencia mundana" (1975: 15). Surge así, en la lectura del corpus cavediano, una línea matriz que acentúa la debilidad de la carne (propensión al deseo y caducidad del cuerpo humano, que enferma y muere), y más aún, cierta afección natural a la descomposición, a la corrupción de lo que es: el humano desea y, en consecuencia, afecta tristemente su composición puesto que la tienta y amenaza; vivir es descomponerse, y de aquí que esa descomposición habilite sólo un camino hacia la muerte, y quizás, sólo

Pinturas y Retratos nunca aparece (solo) como título. En tres de ellos (C, D, E) aparece acompañado por Guerra Física, Proezas Medicales, Hazañas de la Ignorancia, sacadas a la luz del conocimiento por un enfermo que milagrosamente escapó de los errores médicos por la protección de San Roque, abogado contra médicos o contra la peste que tanto monta. Dedícalo su autor a la Muerte, Emperatriz de Médicos, a cuyo augusto pálido cetro le feudan vida y tributan saludes en el tesoro de muertos y enfermos, que sin embargo consta (solo) en otros 3 ( $\mathrm{A}, \mathrm{B}, \mathrm{H}$ ), es decir, que figura 6 veces $(\mathrm{A}, \mathrm{B}, \mathrm{C}, \mathrm{D}, \mathrm{E}, \mathrm{H})$. De los 10 manuscritos que maneja Cáceres, sólo en dos (y en uno de ellos de forma ambigua) se lee Diente, mientras que en 5: Guerra Véase también: Hopkins Rodríguez (1975: 10), Lorente Medina (1992: 299-300) y García-Bedoya (2000: 86). 
dos formas de recorrerlo: suspendiendo el juicio inmediato y sancionando un valor trascendente, afirmando un juicio mediato y sancionando el desvalor inmanente. Pero esto, a mi entender, no constituye una "desconcertante mezcla de fe y escepticismo" (Sánchez, 1951: 60) sino que funda, en buena medida, el usual desconcierto crítico que conduce a atender no de forma conjunta sino de forma confusa el fraccionario corpus amoroso de Valle y Caviedes. Vale decir: el desconcierto crítico hace de Valle y Caviedes -quien, según parece, "sufrió mucho de mal de amor" (Sánchez, 1937: 104)- un escritor "devoto del amor" (Sánchez, 1951: 62); pero dicha devoción hace del poeta, vía yo lírico, tanto un "mujeriego" (Sánchez, 1939: 223), "tentado por la carne prieta, carne de pecado" (225) y "probable víctima del "mal francés"” (223), como un "censor de las costumbres" (Cisneros, 1990: 153), una "conciencia de la fuga del espíritu heroico de su comunidad” (Hopkins Rodríguez, 1975: 7) que propone una "ejemplaridad purgativa" (1975: 15), porque es -esencialmente- un “creyente en Dios" (Sánchez, 1951: 62) y -existencialmente- un poeta, lo que "implica -según el muy particular parecer de Cisneros- un cierto modo de ser auténtico, un hacer frente a la vida tal como ella se nos presenta" (1990: 111). Esta forma confusa y este desconcierto se manifiestan nítidamente en uno de los poemas amorosos más mencionados por la crítica: el que escribió a la muerte de su esposa (el "único texto -según Cisneros-que puede salvarse de todo este conjunto amatorio", 1990: 184). Entre el pícaro mujeriego y el piadoso cristiano surge el "amantísimo marido", se vislumbra esa "sincera devoción que a su mujer profesó” (Sánchez, 1951: 58) y se lee entonces el poema por su "gran validez como documento de un dolor sincero" (Bellini, 1966: 163). Amén de que alguna vez fue puesta en duda su autoría (Sánchez, 1939: 223) y que ha sido repetidamente editado, según Cáceres (en Valle y Caviedes 1990: 601-2), de forma adulterada ${ }^{4}$; e incluso dejando de lado el sentido fuertemente moral de esta maniobra crítica (que pretende legitimar, si no absolver, los placeres sexuales y las marcas del pecado carnal a través del sagrado matrimonio): ¿qué es lo que dice amorosamente ese romance que no digan otros? Esto es: ¿qué hace poéticamente singular a esa composición, donde un yo lírico (tradicionalmente y sin ninguna marca "personal" o distintiva) pena su tan inesperada como inconsolable soledad (vv.1-16), compara su sufrimiento con el de las rocas "que en resistir los males / suplirme pueden, pero no en llorarlos" (vv.19-20), para finalmente, lamentar sombrío la desdicha de una luminosa pérdida (vv.21-8)?

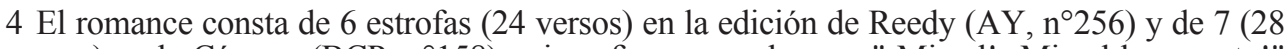
versos) en la Cáceres (BCP, n¹58) quien afirma que el verso "¡Mi sol! ¡Mi sol ha muerto!" (AY, n²56, v.23) no se encuentra en ningún manuscrito (también difieren, aunque menos, los versos $7-8$ y 20 ). 
De una devoción a otra, lo que se descompone es la carne (de una esposa y de las muchas "damas" hospitalizadas), lo que se exhibe es su debilidad (terrena), y en consecuencia, el riesgo del deseo y -especialmente- del deseo amoroso, y lo que compone no son los médicos puesto que la muerte es "soberana de los médicos" (Hopkins Rodríguez, 1975: 14). Y si “jocosamente”-como también afirma Hopkins Rodríguez- "su caricatura" es la que le consagra esa soberanía, no es "en contraposición" que la muerte se presenta como "verdad eterna" en la poética cavediana, es decir, "como realidad fundamental y necesaria para la verdadera vida" (14): burlesca y seriamente, en la poética cavediana la muerte es la consecuencia del deseo, vale decir, la consecuencia de ser humano, puesto que allí (e incluso: originalmente) se halla el pecado, raíz del humano y su deseo tanto como de su descomposición fatal. Se entiende que un tópico frecuente en su poesía (y hasta predilecto de su poética) sea el Memento mori: recuerda que morirás, pues esa es la consecuencia más evidente de ser humano (desear y descomponerse). El vínculo afectivo en la poesía de Valle y Caviedes, como muy claramente supo notar Picón Salas en 1944, expresa el mismo menosprecio del mundo "en las dos formas antitéticas que conoció la cultura de la época: el ascetismo y la sátira" (1978: 142). No se trata de precios y menosprecios opuestos, sino de formas antitéticas de expresarlo: ya satírica, ya ascéticamente. Vale decir: ya afirmando un juicio mediato y sancionando el desvalor inmanente, ya suspendiendo el juicio inmediato y sancionando un valor trascendente.

En cualquier caso, el amor en el corpus cavediano es un signo tan equívoco para la crítica como imaginario para su poética: se trata de una idea confusa de algo que me sucede; pero a diferencia de lo que ocurre con la poesía amorosa sorjuanina, donde la comprensión del deseo (de su capacidad) surge de la inquietud por la causa amorosa, en la poesía de Valle y Caviedes es la muerte, como consecuencia del deseo, lo que conduce a la imaginación amorosa: ya no el principio de lo común (deseo) y sus modos de composición (amorosa), sino un lugar común (muerte) y sus modos de descomposición (materiales). El amor, en el poética cavediana, afecta materialmente, no sólo porque descompone la carne (enfermedad y muerte) sino porque fracciona el corpus según sus materias y modos de descomposición. El amor es, sensiblemente, principio de análisis (no de síntesis): disolución de un conjunto en sus partes. Lo que se transforma en eje del interés poético son las opacidades y equívocos (el amor, su locura y la muerte) y sus miembros (amantes): el efecto incompresible (pero imaginable) de una causa ingobernable (el amor, el deseo amoroso, su descomposición original). 
La distensión-confusión de cuerpo y espíritu, y más aún, la descomposición de la carne como señal y efecto de dicho proceso, evidencia una preocupación poética notoria por la muerte, en tanto afecta el máximo de desintegración y constituye el punto por el que sólo pasan líneas de desfiguración del yo, vale decir, donde ya no es factible convertirse en agente de la propia acción, en tanto la muerte impide o disminuye la capacidad de afección entre partes. La muerte experimenta toda la pasión de la que uno es capaz: colma el poder de afección individual, aunque tristemente. Pero -naturalmente- hay grados: por ende, el problema de la descomposición estriba en el riesgo composicional del vínculo. O también: en el modo del deseo amoroso. Y así, la regulación (reglamentación, codificación) del riesgo se torna necesaria en la poética de Valle y Caviedes.

De esta manera, el romance $\mathrm{n}^{\circ} 78$ titulado "A una dama que prendieron por serlo con demasía" expone el tema o problema tan tradicional de la prostitución y las prostitutas, aunque -ya desde el título- se advierten ciertos cambios: en primer lugar, el tono (oral) de pregón que coloca la enunciación del poema entre la crónica del día y la publicidad comercial, vale decir, entre el registro y la promoción de un hecho; en segundo lugar, el registro jurídico, que coloca el enunciado entre lo consuetudinario y lo legítimo, con su consecuente sanción valorativa; y por último, la "demasía” femenina de la donna/madonna, es decir, el exceso (moral) y "plus-valor" (económico) de la dama que no sólo destaca -vía ironía- un régimen poético de valor distinto y hasta opuesto al de la virtud (cf. Zavala, 1980: 368) sino también -vía lítote- un régimen retórico del menos por más: "una ponderación al revés" (Beristáin, 2004: 305), que operará -principalmente- a través de dilogías o equívocos.

\author{
Pagando culpas de dama \\ de amantes dorados yerros, \\ presa está la que prendía \\ a los mozos y a los viejos. \\ $\left(n^{\circ} 78, v v .1-4\right)$
}

Como se vislumbraba en el título, se anuncia un hecho ("presa está" cierta dama) cuyo registro jurídico es tan evidente como su sentido moral y económico ("pagando sus culpas"). No obstante, y antes de avanzar sobre cuáles sean las "culpas de dama" (v.1), es claro que sólo "la que prendía" (v.3) paga, tanto por damas como por amantes (y en cada caso por razones bien distintas aunque se 
trate -igualmente- de razones erradas o faltas). Así también es claro que, en el vínculo afectivo (dama-amante), las afecciones no son comparables ("culpas" por un lado, "dorados yerros" por el otro), y que si comparten un mismo origen o causa (el deseo, e incluso, el deseo amoroso) y su consecuencia es -igualmente- un incumplimiento o falla (que debe ser resarcido), la falta en la que incurre cada miembro del vínculo no tiene el mismo valor (moral y económico), y por tanto, dicha falta no es juzgada (examinada, calificada y sentenciada) de la misma manera: un yerro hace suponer un descuido que, deliberado o no, es siempre accidental (inesencial); si además se trata de un dorado yerro, puede entenderse que a la falta, si no le asiste cierta gracia, al menos se la reputa positivamente; todo lo cual dictaría cierta inocencia que absolvería, analíticamente, una de las partes. Nuevamente, el eje pasa por "la que prendía" pero que ya no prende, lo que evidencia no sólo el carácter modal del que se ocupa el poema (las "culpas de dama") sino el equívoco doble ("presa está la que prendía") que lo organiza: se trata de "prender" y "apresar", vale decir, de quien enciende y agarra y de quien hace presa y aprisiona. Más precisamente, se trata de dos poderes de captura: el poder del deseo (e incluso del deseo amoroso) que prende y aprende por la carne; y el poder de la justicia que prende y aprende por la ley. Así las “culpas de dama", según consta, "ha sido causa / de muchos levantamientos" (vv.15-6), cuya dilogía (erótico-jurídica) es tan clara como la sentencia que resuelve que, por dichas "causas carnales" (v.43) y "Porque de la carne se hacen / las presas, y esta se ha hecho" (vv.69-70), "no la absolvieron" (v.42).

Sin embargo esto no resuelve el conflicto, o no al menos para el yo lírico.

Dicen que han de desterrarla y fuera justicia hacerlo, si algún lugar de capones hubiera en aqueste Reino. Pues a cualquiera que fuere puede decir por consuelo:

Omnia mea mecum porto llevándose su omnia meo. Mas si yo allá gobernara las volviera aquí, diciendo:

"Sustente cada ciudad las rameras de suelo."

$$
\left(n^{\circ} 78, v v .45-56\right)
$$


La intromisión del yo lírico resulta relevante, no sólo porque en las sátiras amorosas suele posicionarse "por fuera" o "extremo" del enunciado, sino porque su desacuerdo encuentra razón -justamente- allí, esto es, también por "por fuera" o "extremo" de la justicia: "Miren qué harán con aquesta / que es donairosa en extremo, / sino el hacer la justicia / más achaques del remedio" (vv.89-92). El yo lírico juzga que la prisión, e incluso el destierro, "prende" y "apresa" aún más el deseo, ${ }^{5}$ es decir, le da aún más poder de captura, que es -naturalmente- un aumento de su poder de afección; y si afecta más -según se ha visto- más descompone. El refrán, aquí aludido, es bien conocido y hasta tópico, o muy expresivo (Luciani, 1987: 341), en la poética cavediana: resultó peor el remedio que la enfermedad. El deseo amoroso, así presentado, resulta al menos para la justicia ordinaria-ingobernable; y su poder de afección deviene "en extremo" (v.90; cf. también n`245), puesto que sus variables de afección se multiplican, independizándose de la sola belleza: “A muchas quieren por fama / de ser hermosas, sin serlo, / porque también los oídos / vendados tiene el dios ciego" (vv.85-88; cf. también n97). En la analítica amorosa cavediana, se evidencia un deseo de razón (si yo gobernara, v.53) para un poder que excede o extrema, en su totalidad, la simple voluntad (política) y el manifiesto entendimiento (erótico) de sus partes.

Pero el deseo de razón, que es aquí claro deseo de gobierno (deseo de gobierno del deseo), al no saciarse en el vínculo afectivo, cuyo poder de afección excede o extrema sintéticamente sus partes, encuentra -analíticamente- en una de ellas su soporte: se trata, finalmente, de las "culpas de dama". Ahora bien: ¿cuáles son las "culpas de dama"? Son, como ha dicho el yo lírico, "su omnia meo" (v.52): todas sus cosas, las que llevan a todas partes consigo. Omnia mea mecum porto (llevo todas mis cosas conmigo), que Cicerón adjudica a Bías de Priene (Las paradojas de los estoicos, 1.1.8) y Séneca a Estilpón (Epistolas morales, 9.18-19), ${ }^{6}$ refiere-invariablemente- a aquellas "cosas" o "bienes" que uno "tiene", es decir, aquellas cosas que uno es o que hacen de uno quien es."

5 "Su hermosura se adelanta / con tan larga prisión puesto / que da, con lo muy prendido / a su gala más aseo" (vv.73-76) "Con esta prisión añade / a los galanes, deseos, / porque hay amores seguidos / de la fama y el estruendo" (vv.81-84).

6 La frase, como suele suceder, aparece ligeramente distinta en ambas fuentes: "omnia mecum porto mea." (en Cicerón, 2000: 4); y, con dos variantes muy significativas en Séneca:"'omnia' inquit 'bona mea mecum sunt"', que oco después, explica estoicamente: "'Omnia mea mecum sunt': iustitia, virtus, prudentia, hoc ipsum, nihil bonum putare quod eripi possit." (cf. Séneca, 1905: 23)

7 Valerio Máximo, quien también "siguiendo a Cicerón" adjudica la frase a Bías en Factorum et dictorum memorabilium (7.2.ext.3), explica que esas "cosas" o "bienes" son las que se llevan en el pecho, y no en los hombros, para ser estimadas por el alma, no por los ojos ("bona omnia mea mecum porto": pectore enim illa gestabat, non humeris, nec oculis visenda, sed aestimanda animo). 
Vale decir: se trata de aquellas cosas que me constituyen, que me componen tal cual soy, y por tanto, cuya pérdida corresponde a mi descomposición. Dicho de otro modo: las culpas de dama hacen de las damas quienes son, y así como no hay "lugar de capones" en "aqueste Reino" (vv.47-8), ni capón con genitales, no hay dama sin culpa; ergo, se trata de su esencia: ser dama es tener culpa; lo que articula, cuando menos, una diferencia esencial entre amante y dama, si no -trópicamente- entre hombre y mujer (cf. Halperin, 1999). El modelo amoroso petrarquista, incluso de "amor cortés" (cf. Zavala, 1980; Navarrete, 1997; Rose, 2005; Ciordia y Funes, 2012), cambia de norte: la donna es a quien se dona o a quien se da, y así, es culpable de ese don, de esa gracia (exceso y plus-valor), vale decir: de la gracia de ser agraciada, de la gracia de agraciar el deseo, de la gracia natural (dada) de prender y apresar el deseo, incluso de forma artificial (ofreciéndolo sin darlo).

El vínculo afectivo da lugar, de esta manera, a uno de los riesgos composicionales: el del individuo, el de su fragilidad (cf. Foucault, 2003: 3, 56 y 219). La mujer es un riesgo para el individuo, no porque pueda dividirlo, sino porque puede recomponerlo: ese es -según la poética cavediana- su mayor poder de afección. Naturalmente, toda recomposición implica cierta descomposición, y he ahí el riesgo (mortal): el acto sexual, como estudia Foucault (2003), "parece haberse considerado desde hace mucho tiempo como peligroso, difícil de dominar y costoso" (2003: 3, 219-20); pero lo singular del cristianismo (especialmente desde la Contrarreforma) es haberlo convertido en foco permanente de males posibles (cf. Foucault, 2003: 3, 135), como sin duda es el "mal francés". Y la mujer, epítome de la carne, se torna foco de focos, no tanto porque su cuerpo sea distinto sino porque su esencia (alma y cuerpo) es culpable: la mujer lleva esa marca, la del pecado, esa caída que en ella se repite (cf. $\mathrm{n}^{\circ} 79 \mathrm{y} \mathrm{n}{ }^{\circ} 80$ ) y ella purga $\left(n^{\circ} 56\right)$. Vale decir: la mujer está signada por la descomposición y la muerte, y en este sentido es un riesgo -en general-componerse con mujer y doblemente riesgoso -en particular- con una "dama". Toda mujer, bajo cualquier condición (amorosa o jurídica, económica o religiosa) y antes que nada (u originalmente), descompone, introduce la descomposición: des-individua y hace parte. La mujer, también para Valle y Caviedes, es principio de análisis: punto de disolución de un conjunto en sus partes.

Para contrarrestar este mal en ciernes, y contener aún otro peor (el que hace de la simple mujer una "dama”), ¿no es suficiente el casamiento, esa forma legitimada del vínculo afectivo? ¿Implica algún riesgo de composición ese vínculo? ¿No es esa forma de la participación la mejor respuesta al problema de la mujer que, legítimamente casada, disminuye su poder de afección (y su capacidad de volverse "dama", cf. $\mathrm{n}^{\circ} 48$, vv.13-16 y n¹42) e incluso lo doblega 
anónimamente al de su esposo (al convertirse en "la mujer de", como consta en el romance $n^{\circ} 158$, escrito "En la muerte de la mujer del autor")? Nuevamente el yo lírico se posiciona "fuera de" o "extremo" de la justicia ordinaria o razón corriente: el casamiento es claramente, por ser legítimo, un vínculo muy riesgoso; aunque el riesgo composicional en este caso no sea, principalmente, el del individuo. A este asunto se dedican varios poemas (cf. $\mathrm{n}^{\circ} 45,48,112,113$, $115,118-22,139)$; e incluso uno $\left(\mathrm{n}^{\circ} 142\right)$ donde se "dirime" el falso dilema (depreciándose así este tipo de ejercicios) sobre "Cuál sea mejor para mujer propia, la hermosa boba o la fea discreta" (cursivas mías). ${ }^{8}$ El casamiento supone componerse con mujer y eso - esencialmente- ya es un riesgo para el individuo (femenino o masculino). No obstante, el mayor riesgo no radica en el individuo, y no se dirime en el mero acto sexual: el casamiento antepone o, mejor, evidencia la tensión entre un dispositivo de alianza y un dispositivo de sexualidad (cf. Foucault, 2003: 1, 126-139). Vale decir: el riesgo composicional del casamiento no es, estrictamente, el del individuo y su sexualidad sino el de la población y sus alianzas. ${ }^{9}$ El problema no es que una pareja decida casarse, sino que ese casamiento legitime una unión inútil o improductiva socialmente: ese es, tópicamente, el problema del casamiento con viejos, cuya capacidad de afección generativa aparece como muy reducida, y esta "impotencia" (cf. $\left.\mathrm{n}^{\circ} 115\right)$ es un riesgo poblacional que excede pero contiene al individuo. Si "la que prendía" genera muchos "levantamientos", hay un riesgo para el individuo (enfermedad y muerte); si además esos levantamientos generan nuevos individuos, el riesgo ya es poblacional puesto que se trata de vínculos sociales ilegítimos (perversión) cuyos efectos pervierten la herencia (biológica); y si el vínculo es legal pero la unión inútil o improductiva, nuevamente el riesgo es poblacional puesto que se pone en juego la herencia (económica) y la degeneración (social). Perversión, herencia y degeneración (asuntos centrales en constitución de la burguesía, cf. Foucault, 2003: 1, 151) despuntan ya en el siglo XVII como problemas ligados, intensamente, a la carne y a la sangre, a las purgas y purezas, a los médicos y jueces (ambos incapaces, según Valle y Caviedes, de gobernar o regular adecuadamente los riesgos composicionales del deseo).

\footnotetext{
8 Se trata de un falso dilema, menos que por el modo de tratarlo, porque la proposición no presenta un todo dividido en partes antitéticas, o lo que es lo mismo: para "mujer propia" (esposa) es mejor la fea ( ${ }^{\circ} 142$, vv.96-100), porque su poder de afección es menor o controlable; pero para mujer deseada (dama) es mejor, sin ninguna duda, la hermosa (vv.101-105); a fin de cuentas, el hombre no lleva culpa del vínculo, y sea cual fuere el modo del acto cometido, se trata siempre "en su caso" de un "yerro" más o menos "dorado". De distinta manera, este mismo problema (esposa/dama), es el que se dirime en Amado y aborrecido, impresa en 1657, de Calderón de la Barca (cf. Alatorre, 2003: 100-1 y 119).

9 "Obra de tinieblas es / la que en un mismo ejercicio / es útil para la especie / y dañosa al individuo", dice un epigrama de Owen titulado "Generación", atribuido a Valle y Caviedes y entre sus poemas editado (cf. García-Abrines Calvo 1987).
} 
De la corrupción del cuerpo individual (fragilidad del individuo) a la degeneración del cuerpo social (fragilidad de la población), o en el cruce de una "anatomopolítica del cuerpo humano" y una "biopolítica de la población" (Foucault, 2003: 1, 168), se halla el deseo amoroso por el cual la poética cavediana presenta un notable interés (dados sus riesgo composicionales) y una marcada preocupación (por la regulación de los mismos). Esto supone, si no una división entre cuerpo y alma, al menos el establecimiento de cierta "inferioridad del amor por el cuerpo" (Foucault, 2003: 2, 218) de origen platónico: el amor debe dirigirse al alma, más que al cuerpo, porque allí se funda aquello que "determina el ser y la forma de su amor (su deseo de inmortalidad, su aspiración a lo bello en su pureza, la reminiscencia de lo que vio arriba del cielo)." (2003: 2, 218) De alguna manera, "aqueste Reino" (terreno) del que hablaba el yo lírico ( ${ }^{\circ} 78, v .48$ ) impide o desalienta un amor por el cuerpo, en tanto torna riesgosas sus composiciones (vínculos afectivos) e inevitable su descomposición (degeneración, enfermedad, muerte). No obstante, en la otra vertiente de su modalidad lírica parece abrirse un espectro distinto para la poética amorosa cavediana: en la poesía amorosa, a diferencia de lo que ocurría con su sátira amorosa, el yo lírico se coloca "dentro del" enunciado y pasa a ser el amante, frustrado o dolido. En estos poemas el yo lírico se hace sujeto de un amor, tópicamente, no feliz; pero aquí, la no correspondencia amorosa, lejos de entorpecer el deseo, permite desplazar su énfasis del cuerpo (individual o social) hacia sí mismo. Unos tras otros se suceden los lamentos, apenas razonados, y se componen las quejas, sostenidas en tristes juicios. El yo-lírico sufre solo, pero canta, el desencuentro con su amada que es, simultáneamente, un encuentro (desafortunado) consigo mismo. Ciertos tópicos, tradicionales, refuerzan el modelo de tradición petrarquista, ya muy conocido en Perú y practicado en Lima (cf. Hampe Martínez, 1992; Colombí-Monguió, 2007; Rose, 2008; Bellini, 2008): los ojos de la amada son dardos o soles que enceguecen, y sus pies hacen brotar flores al prado al pasar; mientras el enamorado, indefenso, desvaría y padece, y siente incendiarse sin que sus lágrimas alcancen a apagar el fuego que -muy por el contrario- avivan. El amor, tópicamente, se presenta como un mecanismo triste e invariable de reveses y opuestos, que llega incluso a desvincular causas de efectos $\left(n^{\circ} 234\right)$ y reúne, ilógica pero tradicionalmente, los extremos: ${ }^{10}$ todo

10 En el Cancionero de Petrarca (1997) son muy frecuentes y hasta tópicas ciertas antítesis, que "incluso" el yo lírico tematiza: "Amor, por más que tarde lo supiera, / quiere entre dos contrarios consumirme" ( $\left.{ }^{\circ} \mathrm{LV}\right)$; en este sentido, también: "dulce desdén" ( $\left.{ }^{\circ} \mathrm{LXXI}\right)$, "sufrir contento" ( $\left.{ }^{\circ} \mathrm{CCXII}\right)$, "vivir dulce y amargo" ( $\left.{ }^{\circ} \mathrm{CXXIX}\right)$, "vivo dulcemente en la amargura"( $\left.{ }^{\circ} \mathrm{CCCLX}\right)$, 
ocurre -aquí también- muy por el contrario; pero a diferencia de lo que sucedía con las sátiras amorosas donde el remedio (jurídico, médico o erótico) era peor que la enfermedad (carne y "culpas de dama"), en los poemas amorosos se privilegia esencialmente el "alma" antes que el "cuerpo", y en consecuencia, muy por el contrario no hace del remedio enfermedad sino otro de mí. Alma y cuerpo forman la esencia y, como se ha visto, omnia mea mecum porto: no se trata de una separación de alma y cuerpo sino de un privilegio o superioridad del alma; y cabe agregar: del alma masculina. Como se ha visto, en la poética cavediana aparece una diferencia esencial entre amante y dama: uno se define por la culpa propia y el otro no. De esta manera, si el yo lírico es el amante, en los poemas amorosos el asunto no será la culpa ajena (de dama) sino la ajenidad de su culpa, la otredad de sí, que son -ambos y una vez más- efectos (descomposicionales) del vínculo afectivo.

En estos poemas, una y otra vez, retorna la inquietud de sí; pero lo singular aquí es que esa inquietud no pretende dominar el deseo (no se trata-como se ha visto- del deseo de gobierno del deseo) sino que "muy por el contrario", la inquietud que privilegia el alma del amante, exhibe una marcada y tradicional preocupación por su salvación, que - de forma menos tradicional- es una preocupación surgida no de un deseo (poético) sino de un deber (doctrinal): el deber de salvarse. En este sentido, se explica que una de las definiciones del amor sea "él es enigma y laberinto en suma" (n`262, v.14): el sujeto de deseo, el amante, se halla ya agujereado por un Otro (Lacan, 2011: 138) ya escandido por un Otro, “ontológicamente extraño" (Foucault, 2003: 2, 66), y es su deber reconciliarse, "volverse" (Ciordia, 2004: 160-2), armonizar consigo mismo a través de una hermenéutica (enigmática, laberíntica) del deseo propio. Del dominio de sí a la verdad de sí, lo que se busca en el amor ya no es la otra mitad de uno mismo o el dominio del otro, sino "la verdad con la que su alma [la del amante] tiene parentesco" (Foucault, 2003: 2, 223). Y esa búsqueda es un deber porque surge de una necesidad natural que es la de subsistir, la de no descomponerse. Y cabe agregar: armonizar cuerpo y alma en la unidad natural de uno mismo no sólo redefine el vínculo afectivo (entre el humano y su deseo) sino el sentido mismo de vínculo, en tanto no concierne ya a una relación con los demás (vínculo múltiple) ni privilegia el "entre dos" matrimonial (vínculo binario), sino que se centra en la correspondencia con uno, sea la conciencia individual o Dios (vínculo unitario).

"Cupido"-soliloquia el yo lírico en un imaginario diálogo con su "dueño",

entre otros. En la obra poética amorosa de Valle y Caviedes se encuentra, por ejemplo: "Triaca que a mi vida le da muerte / veneno que a mi muerte le da vida, / ¿cómo me animas si eres mi homicida? / ¿cómo de mi desgracia haces mi suerte?" (n²65, vv.1-4). 
es decir, se dice a sí mismo como si fuera otro- "es voz ambigua, falsa" ( ${ }^{\circ} 246$, v.34); y poco después afirma que "Diablo es Amor, no es dios" (v.77). Como señala Luciani, no sólo doctores sino cupidos "curan hiriendo y matando" (1987: 344); aunque una muy antigua tradición epigramática ya decía, según Rufino (s. IV): "Si nos flechas a ambos por igual, eres un dios; si disparas sólo por un lado, no lo eres" (cit. en Alatorre, 2003: 83). Nada más lógico entonces, para hallarse a sí mismo, para armonizar consigo y erradicar esa otredad que lo enajena, que el yo lírico (amante) busque conjurar ese deseo, mantener separado ese mal, purgar ese estigma. ${ }^{11} \mathrm{Y}$ así, equivocidad mediante ("Equívocos son mis versos", n²48, v.1), las amadas o "dueños" de los poemas amorosos de Valle y Caviedes no tardan en aparecer como "tiranas" (n²46, v.36), cuya más frecuente característica será la de reunir cierta tópica "belleza e ingratitud" con una ectópica -e incluso distópica- "razón de estado": "Si el ser bella y ser ingrata / es de amor razón de estado / tirana ley es que sólo / pueden derogar los astros" (n²31, vv.17-20). ${ }^{12}$ La arbitrariedad de la donna se torna así menos irracional que despótica, quizás - como sugería Bajtín- porque se va perdiendo "la antiquísima ambivalencia" del elogio-injuria y por tanto "las palabras afectuosas" se tornan "convencionales y falsas, borrosas, unilaterales y sobre todo incompletas" (1990: 379-80); en consecuencia, el enamorado no espera, si ha de morir de amor, encontrar en la muerte el típico y tópico descanso o reconciliación sino un consuelo muy singular que se enuncia como cierta "venganza" (n`246, v.66): "Yo pondré mis desprecios / encima de tu cara, / y de facciones bellas / haré rostro que incite mis venganzas" ( $n^{\circ} 246$, vv.101-4). Y no sólo una venganza, sino dos, pues la amada seguirá viva, es decir, muriendo (descomponiéndose) y falseando (desfigurándose) cada vez más su tirana existencia en

11 Cabe recordar que Bías de Priene, a quien "como se ha dicho" Cicerón adjudica la frase Omnia mea mecum porto, tenía entre sus máximas la siguiente: "La mayor riqueza es no desear nada" (cf. Cicerón, 2000: CVIII). Quizás por eso, el bien deseado sea "justamente" ningún bien: "Tan hecho estoy a los males / que cualquiera bien me hiciera / mucho mal, que los alivios / nunca usados son violencia." (n॰242, vv.17-20)

12 La "tiranía" de la amada y su "razón de estado" actualiza y problematiza claramente el eje feudal (medieval) del amor cortés habilitando, sin duda, una lectura moderna al tensar las razones del poder con el poder de las razones (sagradas o profanas), como se puede comprobar al leer el siguiente pasaje sobre las ideas políticas de Hobbes: "Nada de lo que Leviatán [amada] hiciere se le puede reprochar pues no es él quien actúa sino todos los súbditos [amantes], a su través, ellos son los responsables últimos de sus actos. La propia naturaleza del pacto hobbesiano otorga el privilegio de la razón o sinrazón de Estado al soberano. Quienes lo suscribieron se comprometieron a la entrega de todo el poder que, incluso, podría llegar a la arbitrariedad sin que, por ello, se le pudiera recriminar nada." (Fernández Ramos, 2012: 313) 
la belleza. ${ }^{13}$ La amada, si sobrevive al enamorado, sólo afea la belleza del amor enfatizando la tiranía de ese estado. El amante en cambio, si pretende armonizar consigo y hallar esa verdad con la que su alma tiene afinidad, vale decir: esa verdad que es y que lo constituye (omnia mea mecum porto), debe tomar distancia de ese mal, conjurar el poder de afección de las "culpas de dama", purgarse del pecado que lo descompone, y en fin, sacarse el diablo (amoroso) no sólo del cuerpo (carne) sino del alma (otredad de sí).

\section{Terapéutica de un afecto irrazonable}

Las piezas teatrales o "bailes" de Valle y Caviedes -breves y similares en su austeridad escénica- articulan, como se dijo, el amor en su modalidad dramática; y no sólo articulan sino que se constituyen literalmente en torno del amor, que funge -en los tres casos- de personaje-centro al que un corro de enamorados consultan o participan, por turno, sus pesares. Y esta forma estructural de los "bailes" es, si rara en Valle y Caviedes, por lo mismo muy elocuente, puesto que se trata de cierta construcción geométrica del problema amoroso o, como afirma Luciani, menos de una "danza macabra" que de un "minué conceptual" (1987: 339): por un lado, hay un centro o eje amoroso por el que pasan, o al que acuden, radiales y hasta simétricos amantes; por otro, predomina si no el razonamiento afectivo -como en los poemas amorosos sorjuaninos-, al menos el sentimiento argumentado, sea en la forma del juicio (donde un Amor-alcalde responde a los enamorados-presos, $\mathrm{n}^{\circ} 268$ ), sea a la manera de un remedio o solución (donde un Amor-médico atiende a los enamorados-enfermos, $\mathrm{n}^{\circ} 266$ ), sea finalmente como desengaño (donde un Amor-crupier baraja y juega las apuestas y experiencias de los enamorados-tahúres, n²67).

En estas piezas teatrales, el diálogo ocupa el lugar del monólogo lamentoso y solitario, y las razones o sensaciones -ya no las simples quejas- escenifican el drama del desconsuelo amoroso. Curiosa pero no casualmente, la teatralización del amor ocurre bajo cierta condición y concesión de razones o ideas (confusas) que los personajes encarnan y exponen, haciendo del drama amoroso menos la manifestación de una sensibilidad dolida o de una atracción incomprensible que

13 "En fin, yo muero de fino, / y tú vives al contrario / de falsa, dándome dos / consuelos en mi fracaso." (n²31, vv.29-32) Y: "A los años apelo, / que me darán venganza, / y aún ahora la logro, / que la edad aun ofende en amenazas. // Mas venganza no quiero / porque así haré villanas / mis finezas, y tú / si no soy fino, quedas disculpada. // Ruego al Cielo te traten / del modo que me tratas, / porque viviendo muera / la que vive muriendo si no mata." (n`246, vv.65-76) 
la representación de una inteligibilidad (entendimiento y voluntad) en crisis, "porque al pensamiento mismo / se le oculta lo que piensa" (n²43, vv.23-4) y no sólo, puesto que tampoco sabe "lo que puede un cuerpo, es decir, (...) qué es lo que puede hacer el cuerpo en virtud de las solas leyes de su naturaleza, y qué es lo que no puede hacer salvo que el alma lo determine" (Spinoza, Ética, III, 2, esc.; 1984: 172). Esta singular percepción de un inconsciente del pensamiento, que tanto para sor Juana como para Spinoza, conduce a una mayor y más precisa comprensión del deseo y que "no consiste solamente en negar cualquier relación de causalidad entre el espíritu y el cuerpo, sino que prohíbe toda primacía de uno de ellos sobre el otro" (Deleuze, 2012: 28), conduce en la poética cavediana en una dirección muy distinta.

La estrategia discursiva del diálogo en estilo directo produce un máximo de ilusión de mímesis gracias a un mínimo de distancia entre el lector o público y lo dicho, efecto que - entre otros- también se sostiene en la dilución de la voz lírica que adelgaza su presencia hasta lograr que -ilusión de ilusiones- "las palabras se sostengan por sí mismas" (Beristáin, 2004: 142). En este sentido, el yo lírico cavediano que se colocaba ya "fuera de" ya "dentro" del enunciado lírico ahora, notablemente, se des-coloca o deslíe en un conjunto de voces que opera según una de las variantes del dialogismo retórico (percontatio), en la que se da un juego de preguntas y respuestas "en que el orador finge mantener un diálogo con la parte contraria o con el público" (Beristáin, 2004: 143). Sucede que en estas piezas los personajes (amantes), liberados de la tiranía de la amada o conjurado -circunstancialmente- el vínculo que los sometía a esa despótica "razón de estado" (amorosa), intentan reconciliarse consigo mismos e incluso con sus propios discursos (Luciani, 1987: 340), y así buscan purgar o desaprisionarse del mal que los constriñe a padecer. Y esta reconciliación, esta armonización que obliga -como se ha visto- a erradicar el deseo que enajena al amante, tiene también su razón de estado, aunque se trate ahora de una -tan novedosa como ascética y doctrinal- razón de estado de sí mismo. Así la presentó Gracián en El Héroe: "Aquí tendrás una, no política ni aun económica, sino una razón de estado de ti mismo, una brújula de marear a la excelencia, un arte de ser ínclito con pocas reglas de discreción" (1943: I, 3). ${ }^{14}$ Como se ve, si al pensamiento mismo se le oculta lo que piensa, e incluso aquello de lo que es capaz un (su) cuerpo,

14 "La novedad y modernidad del proyecto graciano fue imaginar la utilización del concepto de razón de Estado en el plano individual. La buena razón de Estado a nivel personal, la "razón de ti mismo", supone la traslación de los consejos y modos de actuar de los políticos cristianos a la esfera privada. Si todos los actos del príncipe deben estar informados por la moral cristiana, en la vida ordinaria del hombre, la máxima del actuar debe, asimismo, asumir la ética cristiana para forjar un modo político de actuación" (Fernández Ramos, 2012: 320) 
¿qué mejor solución que "la creación de un superior tribunal de la conciencia, de un fuero interno" (De la Flor, 2009: 243)? En este sentido, cabe afirmar que la modalidad dramática de la poética amorosa de Valle y Caviedes no sólo organiza un teatro interior que, a través de un "casuismo bañado en un tinte jesuítico" (Fernández Ramos, 2012: 317), persuade y dirige la construcción de ciertas conciencias "enajenadas" por el deseo; sino que esas conciencia enajenadas que pugnan por un gobierno de sí (por una razón de estado de sí mismos) "representan" la descomposición del yo lírico, e incluso: del sí lírico que (descompuesta la mismidad de su voz) se imagina dramáticamente en otros (personajes).

La recomposición de sí a través de un fuero interno o teatro interior no sólo se funda en la eliminación del deseo (agente del vínculo afectivo) ${ }^{15}$ sino -sólidamente- en un deber, el deber de sí, que es un deber ser, vale decir, el deber ser razón sí. De esta forma, ese deber se expresa -nítidamente en la poética de Valle y Caviedes- como una terapéutica o arte de curar: el deseo, al poner en relación, descompone o amenaza la unidad del ser humano (cuerpo y espíritu), es decir, afecta al individuo bajo condición vincular: lo hace sentirse otro, fantasear un otro de sí (paciente u objeto de un poder ajeno u externo); ${ }^{16}$ y si la consecuencia del deseo es desvincularse de sí, es decir, descomponerse (padecer y morir), no hay otra salvación, otro tratamiento (Luciani, 1987: 342), otro deber que el de desvincularse forzosamente del deseo, vale decir, obligar la recomposición de sí con unas pocas y discretas reglas (mandamientos) ${ }^{17}$ : si no se comprende (prende y aprende) el deseo amoroso y no puede gobernarse su poder de afección, se obligará a desprenderse de él legítimamente, se enseñará a desafectar el vínculo analíticamente, y así, se conducirá a cada quien a ser quien es terapéuticamente, pues ese es -más allá de razones y gustos- el deber de cada uno, vale decir, ser uno consigo mismo.

15 "Venga quien / queriendo quisiere / dejar de querer" (n²66, vv.5-7)

16 "La diferencia entre literatura y clínica, lo que hace que una enfermedad no sea una obra de arte, es el tipo de trabajo que se realiza sobre la fantasía. ( ) trabajo artístico o trabajo patológico" (Deleuze, 2005: 174).

17 "Nuevas leyes de amor / he de dar desde hoy, supuesto / que en el imperio del gusto / soy legislador supremo" (n²68, vv.12-5). El poema n¹29, tras una breve introducción ("Atended, amadores del Rimac, / este nuevo y raro pregón, / que Cupido en las leyes del gusto / deroga en aqueste por legislador", vv.1-4), alterna un estribillo ("Porque sí, porque no / porque quiere Cupido / que es rey del amor") con una ristra mandamientos amorosos (20 en total), sólo interrumpida por una derogación (v.11), que se organizan a través de una "elocuente" forma anafórica (sólo una vez elidida, v.67): "Manda" (v.4, v.18, v.25, v.32, v.39, v.46, v.53, v.60, v.74, v.81, v.88, v.95, v.103, v.109, v.116, v.123, v.130, v.137, v.144). Este devenir religioso de la pasión amorosa tiene no sólo numerosos antecedentes sino un efecto (moderno) muy atendible "mediante el cual se seculariza lo religioso y a la vez que se cristianiza lo profano." (Funes, 2012: 164). 
Como ocurre en la poética amorosa sorjuanina, también en la cavediana el amor es una idea confusa de algo que, ciertamente, me sucede y que no puedo explicar ni con el entendimiento ni por la voluntad: "Al Amor nadie lo entiende / porque su cautela es / no ser de nadie entendido / para dar más a entender" (n²66, vv-103-6). Sin embargo, esa idea confusa y ese suceso cierto no obran en Valle y Caviedes una comprensión del deseo sino un tratamiento del deber. Ese más a entender expresa -al fin- ya un deseo ya un deber, y en ambos casos, una misma inquietud por "eso" que sucede cuando el amor ocurre (me ocurre y se me ocurre). Y si para sor Juana "eso" da cuenta de un principio de lo común (agente de compresión) y de un poder de composición muy singular; para Valle y Caviedes "eso" mismo da cuenta de un lugar común (agente de imaginación) y de un inevitable poder de descomposición, ante el cual su poesía no es capaz de hallar razones, sino alternativas terapias.

Recebido em: 12.05.2016 Aprovado em: 30.07.2016

Alatorre, Antonio (2003). "Un tema fecundo: las 'encontradas correspondencias", en Nueva Revista de Filología Hispánica, 51: 81-146.

Bajtín, Mijaíl (1990). La cultura popular en la Edad Media y el Renacimiento (Versión de Julio Forcat y César Conroy), México DF, Alianza.

Bellini, Guiseppe (1966). “Actualidad de Juan del Valle y Caviedes”, en Caravelle, 7: 153-164.

(2008). “Italia, España, Hispanoamérica: una comunidad literaria renacentista". Edición digital: Alicante, Biblioteca Virtual Miguel de Cervantes. En: Studi di Letteratura ispano-americana, Estratto, 33, Roma, Bulzoni, [s.a.]: 45-60.

Beristáin, Helena (2004). Diccionario de retórica y poética, México DF, Porrúa.

Bruno, Giordano (2007). De los vínculos en general (trad. Ezequiel Gatto), Buenos Aires, Cactus.

Cabanillas Cárdenas, Carlos F. (2009). "De nuevo sobre el corpus de poemas antigalénicos de Juan del Valle y Caviedes", en Ignacio Arellano y Antonio Lorente Medina (eds.), Poesía satírica y burlesca en la Hispanoamérica colonial, Madrid, Iberoamericana-Vervuert: 59-76.

Cicerón, Marco Tulio (2000). Las paradojas de los estoicos (trad. Julio Pimentel Álvarez), México DF, UNAM.

Ciordia, Martín (2004). Amar en el Renacimiento, Buenos Aires, Miño y Dávila.

(2012). “Amar según Petrarca”, en Martín Ciordia y Leonardo Funes (comps.), El amor y la literatura en la Europa bajomedievel y renacentista, Buenos Aires, Colihue: 35-53.

Ciordia, Martín y Leonardo Funes (2012). "Introducción”, en Martín Ciordia y Leonardo Funes (comps.), El 
amor y la literatura en la Europa bajomedievel y renacentista, Buenos Aires, Colihue: 7-32.

Cisneros, Luis Jaime de (1990). "Estudio crítico", en Juan del Valle y Caviedes, Obra completa, Lima, Banco de Crédito del Perú: 95-210.

Colombí-Mongió, Alicia de (2007). "Del Generalife hacia América", en Injerto peregrino de bienes y grandezas admirables, México DF, UNAM.

De la Flor, Fernando R. (2009). Imago. La cultura visual y figurativa del barroco, Madrid, Abada.

Deleuze, Gilles (2012). Spinoza: Filosofía práctica (trad. Antonio Escohotado), Buenos Aires, Tusquets.

(2005). La isla desierta y otros textos (versión de José L. Pardo), Valencia, Pre-Textos.

Fernández Ramos, José Carlos (2012). "Hobbes, Gracián, y la Razón de Estado”, en Intersticios, 6-2: 309-321.

Foucault, Michel (2003). Historia de la sexualidad (3 tomos), Buenos Aires, Siglo XXI.

Funes, Leonardo (2012). "Tradiciones líricas y tradiciones narrativas del amar en la Castilla del siglo XV", en Martín Ciordia y Leonardo Funes (comps.), El amor y la literatura en la Europa bajomediavel y renacentista, Buenos Aires, Colihue: 147-170.

García-Abrines Calvo, Luis (1987). “Consideraciones sobre unos epigramas de Owen atribuidos a Valle y Caviedes", en Revista de Filología Española, vol. LXXI, 3-4: 355-361.

García-Bedoya M., Carlos (2000). La literatura peruana en el período de estabilización colonial (1580-1780), Lima, UNMSM.

Gracián, Baltasar (1943). Obras completas (3 tomos: trad. Ulises Guiñazú, Martí Soler, Tomás Segovia), Bue- nos Aires, Poblet.

Halperin, David (1999). ¿Por qué Diótima es mujer? El erôs platónico y la representación de los sexos (trad. Mariano Serrichio), Córdoba (Argentina), El cuenco de plata.

Hampe Martínez, Teodoro (1992). "El eco de los ingenios: literatura española del Siglo de oro en las bibliotecas y librerías del Perú colonial", en Revista de Estudios hispánicos, 19: 191-209.

Hopkins Rodríguez, Eduardo (1975). "El desengaño en la poesía de Juan del Valle y Caviedes", en Revista de Crítica Literaria Latinoamericana, 2: 7-19.

Lacan, Jacques (2011). El seminario. Libro XX. Aún (trad. Diana Rabinovich, Delmont-Mauri y Julieta Sucre), Buenos Aires, Paidós.

Lorente Medina, Antonio (2005). "La transmisión textual de la poesía de Juan del Valle y Caviedes: bases para su estudio", en Carlos Mata y Miguel Zugasti (eds.), Actas del Congreso "El Siglo de Oro en el Nuevo Milenio" (t. II), Pamplona, Eunsa: 1069-1088.

(1992). "La parodia en los preliminares de la obra poética de Don Juan del Valle y Caviedes", en Anales de literatura hispanoamericana, 21: 297-307.

Luciani, Frederick (1987). "Juan del Valle y Caviedes: El Amor médico", en Bulletin of Spanish Studies, 64: 337-348.

Navarrete, Ignacio (1997). Los huérfanos de Petrarca, Madrid, Gredos.

Petrarca, Francesco (1997). Cancionero (2 tomos; ed. bilingüe, traducción de Jacobo Cortines), Madrid, Cátedra.

Picón Salas, Mariano (1978). De la conquista a la independencia, México DF, FCE.

Rose, Sonia V. (2008). "Hacia un estudio de las élites 
letradas en el Perú virreinal: el caso de la Academia Antártica”, en Jorge Myers (ed.), Historia de los intelectuales en América Latina (vol. I). Madrid, Katz: 79-93.

(2005). "Petrarca en los Andes: la 'Canción al Perú' de Enrique Garcés”, en Beernard Lavallé (ed.), Máscaras, tretas y rodeas del discurso colonia en los Andes, Lima, Institut Français d'Études Andines/Pontificia Universidad Católica del Perú: 85-120.

Ruiz, Facundo (2015). "Sor Juana crítica: su Crisis. Ética demostrada según el orden teológico", en Bibliographica americana, 11: 101-117.

(2014). "Prólogo", en sor Juana Inés de la Cruz, Nocturna mas no funesta. Poesía y cartas, Buenos Aires, Corregidor: 11-72.

(2009). "Para leer a Juan del Valle y Caviedes", en Noé Jitrik (comp.), Revelaciones imperfectas, Buenos Aires, NJ editor: 319-325.

Sánchez, Luis Alberto (1937). Breve historia de la literatura americana, Santiago de Chile, Ercilla.

(1951). La literatura peruana, Asunción del

Paraguay, Guarania.

(1939). “Un Villon criollo”, en Nosotros, IV-

$\mathrm{X}: 219-226$.

Scavino, Dardo (2010). “Giordano Bruno, De Vinculis in genere (1591)", en Escritores del mundo, 1 [www. escritoresdelmundo.com]

Séneca, Lucio A. (1905). Epístolas morales (trad. de Francisco Navarro y Calvo), Madrid, Imprenta de los sucesores de Hernando.

Spinoza, Baruch (1984). Ética demostrada según el orden geométrico (introducción, traducción y notas de Vidal Peña), Buenos Aires, Orbis-Hyspamerica.
Valle y Caviedes, Juan del (1984). Obra completa (edición, prólogo, notas y cronología: Daniel R. Reedy), Barcelona, Ayacucho.

(1990). Obra completa (edición de María Leticia Cáceres; estudios de Luis Jaime Cisneros y Guillermo Lohmann Villena), Lima, Banco de Crédito del Perú.

Zaffaroni, Eugenio Raúl (2012). La Pachamama y el humano, Buenos Aires, Colihue-ed. Madres de Plaza de Mayo.

Zavala, Iris (1980). "Burlas al amor", en Nueva Revista de Filología Hispánica, 29: 367-403. 